\title{
Insights Into the Ecology of Grapevine red blotch virus in a Diseased Vineyard
}

\author{
Elizabeth J. Cieniewicz, ${ }^{\dagger}$ Sarah J. Pethybridge, Gregory Loeb, Keith Perry, and Marc Fuchs
}

First, second, and fifth authors: Section of Plant Pathology and Plant-Microbe Biology, School of Integrative Plant Science, Cornell University, and third author: Department of Entomology, Cornell University, New York State Agricultural Experiment Station, Geneva, NY 14456; and fourth author: Section of Plant Pathology and Plant-Microbe Biology, School of Integrative Plant Science, Cornell University, 334 Plant Science, Ithaca, NY 14853.

Accepted for publication 12 September 2017.

\begin{abstract}
Limited information is available on the spread of Grapevine red blotch virus (GRBV, genus Grablovirus, family Geminiviridae) in vineyards. To investigate ecological aspects of red blotch disease spread, sticky cards to catch flying insects were placed in 2015 (April to November) and 2016 (March to November) in a vineyard study site in California where disease incidence increased by nearly $20 \%$ between 2014 and 2016. Subsets of insect species or taxa were removed from sticky card traps and individual specimens were tested for the presence of GRBV by multiplex polymerase chain reaction. GRBV was consistently detected in Spissistilus festinus (Membracidae), Colladonus reductus (Cicadellidae), Osbornellus borealis (Cicadellidae), and a Melanoliarus sp. (Cixiidae). Populations of these four candidate vectors
\end{abstract}

ABSTRACT

Red blotch is an emerging viral disease of grapevine (Vitis spp.) that is threatening vineyard profitability (Cieniewicz et al. 2017a; Sudarshana et al. 2015). In red-berried cultivars of Vitis vinifera, red blotch symptoms are similar to those elicited by leafroll disease, damage due to mite feeding, and nutritional disorders such as potassium or phosphorous deficiency. In white-berried $V$. vinifera cultivars, red blotch disease symptoms are similar to those of leafroll or magnesium deficiency. Delayed fruit ripening and reduced fruit qualities are also characteristic of red blotch disease (Cieniewicz et al. 2017a; Sudarshana et al. 2015). The estimated economic impact of the disease ranges from $\$ 2,213$ to $\$ 68,548$ per hectare over the 25-year lifespan of Cabernet Sauvignon and Merlot vineyards (Ricketts et al. 2017).

Grapevine red blotch virus (GRBV) was identified in diseased vines in 2011 (Al Rwahnih et al. 2013; Krenz et al. 2012) and later demonstrated as the causative agent of red blotch disease (Fuchs et al. 2015). GRBV is the type member of the genus Grablovirus in the family Geminiviridae (Varsani et al. 2017). Its genome consists of a single molecule of circular, single-stranded DNA (Cieniewicz et al. 2017a; Krenz et al. 2012; Sudarshana et al. 2015). Phylogenetic studies of GRBV isolates revealed the existence of two distinct clades, named 1 and 2, with nucleotide sequence differences of up to $8.5 \%$ (Krenz et al. 2014). GRBV is transmissible by grafting (Al Rwahnih et al. 2013; Poojari et al. 2013) and vegetative propagation, which may explain its distribution in all major viticulture regions of the United States (Krenz et al. 2014). GRBV has also been reported in Canada (Poojari et al. 2017), Switzerland (Reynard 2015), South Korea (Lim et al. 2016), and India (GenBank accession number KU522121).

${ }^{\dagger}$ Corresponding author: E. Cieniewicz; E-mail: ejc238@cornell.edu

*The $\boldsymbol{e}$-Xtra logo stands for "electronic extra" and indicates that one supplementary figure and one supplementary table are published online.

(c) 2018 The American Phytopathological Society peaked from June to September, with viruliferous $S$. festinus peaking from late June to early July in both years. An assessment of co-occurrence and covariation between the spatial distribution of GRBV-infected vines and viruliferous insects identified a significant association only with viruliferous $S$. festinus. These findings revealed the epidemiological relevance of $S$. festinus as a vector of GRBV in a vineyard ecosystem. Sequencing coat protein and replicaseassociated protein gene fragments of GRBV isolates from newly infected vines and viruliferous vector candidates further suggested secondary spread primarily from local sources and occasionally from background sources.

Additional keywords: spatial analysis.

The primary inoculum responsible for GRBV epidemics in most vineyards is likely attributed to dissemination of infected planting material (Krenz et al. 2014; Sudarshana et al. 2015). However, the mechanisms responsible for the secondary spread of GRBV within and between vineyards are unknown. A comprehensive understanding of the epidemiology of red blotch is critical for effective disease management. Short-distance spread has been observed in some vineyards in the western United States, and attributes of the spatiotemporal distribution of diseased vines suggest a new type of grapevine virus vector (Cieniewicz et al. 2017b). GRBV was also detected in free-living vines proximal to commercial vineyards in California (Perry et al. 2016). These results were subsequently confirmed in an independent study (Bahder et al. 2016b), providing additional evidence of spread by an insect vector. This hypothesis is strengthened by the very high nucleotide sequence identities of GRBV isolates recovered from free-living and proximal V. vinifera 'Merlot' and, to a lesser extent, $V$. vinifera 'Cabernet franc' vines (Perry et al. 2016).

The Virginia creeper leafhopper (Erythroneura ziczac (Walsh)) (Poojari et al. 2013) and the three-cornered alfalfa treehopper (Spissistilus festinus (Say)) (Bahder et al. 2016a) have been shown to transmit GRBV from infected to healthy vines under greenhouse conditions. Neither of these findings has yet been confirmed in a vineyard ecosystem. Moreover, the transmission ability of E. ziczac was recently refuted (Bahder et al. 2016a). Therefore, the epidemiological significance of $S$. festinus and E. ziczac is unknown, stressing the need for vector ecology studies in diseased vineyards. The primary objectives of this study were to investigate ecological aspects of GRBV in a commercial vineyard in which spread was documented (Cieniewicz et al. 2017b) and to characterize the diversity and seasonal distribution of potential hemipteran insect vectors as well as their spatial association with GRBV-infected vines.

\section{MATERIALS AND METHODS}

Vineyard study site and experimental design. A 2-ha $V$. vinifera 'Cabernet franc' vineyard established in 2008 in Napa 
County, CA was selected for this study. Selection of this vineyard was based on temporal changes in GRBV incidence, with spatiotemporal analysis of epidemics suggesting the presence of secondary spread between 2014 and 2016 by an unknown vector (Cieniewicz et al. 2017b). The spatial pattern of diseased vines was characterized by a significant edge effect adjacent to a wooded riparian area and randomly distributed, diseased vines throughout the remainder of the vineyard (Cieniewicz et al. 2017b).

In this Cabernet franc vineyard, vines are spaced 1.2 and $2.1 \mathrm{~m}$ within and between rows, respectively. The study area was positioned at the edge of the Cabernet franc vineyard adjacent to a riparian area. Yellow sticky cards $(7.6$ by $12.7 \mathrm{~cm})$ were placed on the middle trellis wire (1.2 $\mathrm{m}$ above the ground) throughout a sampling area that spanned 12 rows and six four-vine panels per row. The four-vine panels in the sampling area were designated A to $\mathrm{F}$, with panel A positioned at the edge of the vineyard and panel $\mathrm{F}$ furthest into the vineyard (Supplementary Fig. S1). In each row, a sticky card was placed in every other panel (A-C-E and B-D-F) in alternating rows, such that each of the 12 rows contained three sticky cards in either A-C-E or B-D-F orientation. The spacing of two sticky cards between two four-vine panels was approximately $10 \mathrm{~m}$, and the spacing between the first and last sticky card in any given row was approximately $20 \mathrm{~m}$. Sticky cards were removed weekly, placed in plastic bags, shipped overnight from the vineyard to the laboratory in Geneva, NY for evaluation, and replaced with new sticky cards. The survey was conducted from April to November 2015 and March to November 2016 to span the entire growing season.

Insect identification and specimen handling. Insects caught on sticky card traps were identified to genus and species when possible, based on morphological characteristics. Specimens were identified and counted while still attached to sticky cards. The number and identity of specimens were recorded for each sticky card to evaluate the abundance and diversity of flying insects. Of approximately 134,000 insects caught on sticky card traps in both years, 960 (700 and 260 in 2015 and 2016, respectively) were tested for GRBV by multiplex polymerase chain reaction (PCR) (Krenz et al. 2014). Insects in high abundance (Erythroneura spp. and members of families Phylloxeridae, Aleyrodidae, Aphididae, and Thysanoptera) were randomly sampled from sticky cards spanning the entire growing season for testing in both years. For hemipteran insects of low abundance $(<0.25 \%$ of total specimens), every specimen was removed from sticky cards in 2015 and 2016 for PCR testing (Krenz et al. 2014). Specimens were individually removed from sticky cards using Goo Gone liquid degreaser (Weiman Products, Gurnee, IL) to dissolve the adhesive and loosen the specimens. Individual specimens were stored at $-20^{\circ} \mathrm{C}$ until testing by multiplex PCR for GRBV detection (Krenz et al. 2014) or species identification by sequencing of the mitochondrial DNA barcode region (Hebert et al. 2003).

GRBV detection in insects. Total DNA was isolated from individual specimens removed from the sticky cards using the E.Z.N.A Insect DNA kit (OMEGA Biotek, Norcross, GA) and stored at $-20^{\circ} \mathrm{C}$. Diagnostic multiplex PCR was performed using primers targeting a coat protein $(C P)$ gene fragment and a replicase-associated protein (Rep) gene fragment (Krenz et al. 2014). PCR were carried out with HotStar HiFidelity polymerase (Qiagen, Carlsbad, CA) and manufacturersuggested conditions in a C1000 Touch Thermal Cycler (Bio-Rad Laboratories, Hercules, CA). DNA amplification products were resolved by electrophoresis on $2 \%$ agarose gels in $1 \times$ Tris-acetateEDTA buffer and stained with GelRED (Biotium, Fremont, CA). The detection of GRBVamplicons in species or taxa was assumed to result from virus ingestion. Species or taxa for which more than $40 \%$ of the specimens tested positive for GRBV in PCR were considered vector candidates.

Sequence-based insect identification. To provide confirmatory evidence for the morphology-based identification of some insect species, mitochondrial cytochrome $\mathrm{C}$ oxidase gene I (COI) barcodebased identification was performed for identification of vector candidate species. A 650-bp region of the $3^{\prime}$ end of the COI gene was targeted for PCR amplification. Primers LepF2-t1 and LepR1 (Foottit et al. 2014; Hebert et al. 2004) were used to amplify the barcode region of the later identified Melanoliarus sp. Primers LCO1490 and HCO2198 (Folmer et al. 1994) were used to amplify the barcode region of the later identified Osbornellus borealis and S. festinus. PCR were performed and confirmed by gel electrophoresis, as described above. PCR products were sequenced at the Cornell Biotechnology Resource Center in Ithaca, NY and assembled using the DNASTAR Lasergene software suite, version 14.1.

GRBV sequence diversity from vector candidates and infected vines. In order to determine the genetic relatedness of GRBV isolates recovered from the vector candidates caught on sticky cards to the GRBV isolates recovered from newly infected vines in the Cabernet franc vineyard in 2016, the GRBV Rep and $C P$ fragments were amplified from infected vines and insects carrying GRBV. Primers Repfor and Reprev or CPfor and CPrev were used to amplify GRBV Rep or $C P$ fragments, respectively, in simplex PCR using conditions as described above. GRBV Rep and $C P$ fragments were amplified from each vine in the Cabernet franc vineyard that tested GRBV positive in $2016(n=174)$, and each of the viruliferous vector candidate specimens captured in 2015 and $2016(n=82)$. Simplex PCR amplicons were sequenced as described above and aligned with previously sequenced Rep and $C P$ fragments of GRBV isolates recovered from the same Cabernet franc vineyard and proximal free-living grape plants (Perry et al. 2016) using ClustalW (Thompson et al. 1997). Phylogenies were constructed using the neighbor-joining method (Saitou and Nei 1987) after bootstrapping (1,000 simulations) to estimate branching robustness in Megalign (DNASTAR Lasergene software suite, version 14.1).

Spatial distribution of GRBV-infected vines and insect vector candidates. The spatial pattern of diseased vines and GRBVpositive insect vector candidates was analyzed using the spatial analysis by distance indices (SADIE) algorithm (Cieniewicz et al. 2017b; Li et al. 2012; Perry 1995, 1998; Perry et al. 1999; Xu and Madden 2005). Spatial association between GRBV incidence and each of the individual candidate vectors was first evaluated with the local clustering index $\left(\chi_{k}\right)$ calculated through SADIE (Perry 1998). Insect count data were arranged by vine panel, corresponding to the location of the sticky card in each panel in the vineyard. Similarly, panels of vines were arranged by scores of 0 to 4 based on the number of diseased vines in each four-vine panel, with 0 indicating no diseased vine in the panel and 4 indicating four diseased vines in the four-vine panel. Clustering indices represent the net distance that individuals need to move at each sampling unit to achieve regularity. This index is a measure of the similarity between the clustering indices for the two variables measured "locally", at the level of the sampling unit (Winder et al. 2001). Overall spatial association was calculated as the mean of the local clustering indices $(X)$ between either of the two variables of interest. The significance of $X$ was tested by 9,999 randomizations with values of the local clustering indices after allowing for small-scale spatial autocorrelation in the local clustering indices within either population (Dutilleul et al. 1993) and using a two-tailed test (Winder et al. 2001). The null hypothesis used for each test was a lack of association between spatial patterns of diseased vines and viruliferous insects.

\section{RESULTS}

GRBV detection in insects. GRBV was detected in at least $40 \%$ of S. festinus (family Membracidae), Colladonus reductus (family Cicadellidae), O. borealis (Cicadellidae), and a Melanoliarus sp. (family Cixiidae) by multiplex PCR (Table 1). This result revealed that specimens of these four hemipteran species visited the study vineyard and ingested GRBV over two consecutive years. The four insects are hereafter referred to as vector candidates. GRBV was not found by multiplex PCR in the majority of other insects tested over two consecutive years, or it was found in only a few specimens (3 to 8\%) of a limited number of insects (Table 1). GRBV 
was not detected in any of the E. ziczac specimens tested in 2016 (Table 1).

Diversity of insects on sticky card traps. Insect vector candidates (S. festinus, $C$. reductus, $O$. borealis, and a Melanoliarus spp.) collectively comprised only $0.14 \%$ of specimens on sticky cards in both years (87 of 62,128 in 2015 and 99 of 72,242 in 2016), and $0.4 \%(87$ of 18,525$)$ and $0.6 \%$ (99 of 16,060) of Hemiptera on sticky cards in 2015 and 2016, respectively (Fig. 1). Thysanoptera were most abundant in both years and the abundance of Diptera was consistent across years (Fig. 1). More Phylloxeridae were caught in 2015 than in 2016, whereas the abundance of Aphididae was higher in $2016(11 \%)$ than in $2015(<2 \%)$. Overall, Hemiptera comprised less than 23 and $30 \%$ of specimens on sticky cards in 2015 and in 2016, respectively (Fig. 1).

TABLE 1. Grapevine red blotch virus (GRBV) detection in insects trapped on sticky cards in 2015 and 2016 in a Vitis vinifera 'Cabernet franc' vineyard in which secondary disease spread was previously documented (Cieniewicz et al. 2017b)

\begin{tabular}{|c|c|c|c|c|c|c|}
\hline \multirow[b]{3}{*}{ Order, family, genus, species } & \multicolumn{6}{|c|}{ GRBV detection ${ }^{\mathrm{a}}$} \\
\hline & \multicolumn{2}{|c|}{2015} & \multicolumn{2}{|c|}{2016} & \multicolumn{2}{|c|}{ Cumulative } \\
\hline & $n$ & $\%$ & $n$ & $\%$ & $n$ & $\%$ \\
\hline \multicolumn{7}{|l|}{ Membracidae } \\
\hline Spissistilus festinus & $12 / 25$ & 48 & $13 / 25$ & 52 & $25 / 50$ & 50 \\
\hline \multicolumn{7}{|l|}{ Cixiidae } \\
\hline Melanoliarus sp. & $4 / 8$ & 50 & $10 / 12$ & 83 & $14 / 20$ & 70 \\
\hline Colladonus reductus & $14 / 23$ & 61 & $12 / 41$ & 29 & $26 / 64$ & 41 \\
\hline Scaphytopius magdalensis & $3 / 45$ & 7 & $2 / 17$ & 12 & $5 / 62$ & 8 \\
\hline Empoasca sp. & $1 / 28$ & 4 & $1 / 16$ & 6 & $2 / 44$ & 5 \\
\hline Graphocephala atropunctata & $1 / 23$ & 4 & $0 / 14$ & 0 & $1 / 37$ & 3 \\
\hline Erythroneura variabilis & $0 / 22$ & 0 & $0 / 22$ & 0 & $0 / 44$ & 0 \\
\hline Euscelis sp. & $0 / 33$ & 0 & $0 / 11$ & 0 & $0 / 44$ & 0 \\
\hline Erythroneura elegantula & $0 / 41$ & 0 & $0 / 24$ & 0 & $0 / 65$ & 0 \\
\hline E. ziczac & - & - & $0 / 10$ & 0 & $0 / 10$ & 0 \\
\hline E. tricincta & - & - & $0 / 2$ & 0 & $0 / 2$ & 0 \\
\hline Typhlocyba sp. & $0 / 5$ & 0 & $0 / 6$ & 0 & $0 / 11$ & 0 \\
\hline Unidentified species 1 & $0 / 23$ & 0 & $0 / 6$ & 0 & $0 / 29$ & 0 \\
\hline Unidentified species 2 & $0 / 16$ & 0 & - & - & $0 / 16$ & 0 \\
\hline Unidentified species 3 & $0 / 4$ & 0 & - & - & $0 / 4$ & 0 \\
\hline Unidentified species 4 & $0 / 1$ & 0 & $0 / 1$ & 0 & $0 / 1$ & 0 \\
\hline Unidentified species 5 & $0 / 7$ & 0 & - & - & $0 / 7$ & 0 \\
\hline Unidentified species 6 & $0 / 4$ & 0 & - & - & $0 / 4$ & 0 \\
\hline Unidentified species 7 & $0 / 3$ & 0 & - & - & $0 / 3$ & 0 \\
\hline Unidentified species 8 & $0 / 2$ & 0 & - & - & $0 / 2$ & 0 \\
\hline Unidentified species 9 & $0 / 2$ & 0 & - & - & $0 / 2$ & 0 \\
\hline Unidentified species 10 & $0 / 12$ & 0 & - & - & $0 / 12$ & 0 \\
\hline Unidentified species & $0 / 22$ & 0 & $0 / 10$ & 0 & $0 / 32$ & 0 \\
\hline \multicolumn{7}{|l|}{ Psyllidae } \\
\hline Unidentified species & $0 / 25$ & 0 & $0 / 5$ & 0 & $0 / 30$ & 0 \\
\hline Miridae & & & & & & \\
\hline Lygus sp. & $1 / 16$ & 6 & - & - & $1 / 16$ & 6 \\
\hline Lygaeidae & & & & & & \\
\hline Nysius raphanus & $0 / 8$ & 0 & - & - & $0 / 8$ & 0 \\
\hline Thysanoptera & & & & & & \\
\hline Unidentified species & $0 / 36$ & 0 & - & - & $0 / 36$ & 0 \\
\hline Psocoptera & & & & & & \\
\hline Unidentified species & $0 / 12$ & 0 & - & - & $0 / 12$ & 0 \\
\hline Coleoptera & & & & & & \\
\hline Unidentified species & $0 / 24$ & 0 & - & - & $0 / 24$ & 0 \\
\hline Diptera & & & & & & \\
\hline Unidentified species & $0 / 24$ & 0 & - & - & $0 / 24$ & 0 \\
\hline Hymenoptera & & & & & & \\
\hline Unidentified species & $0 / 24$ & 0 & - & - & $0 / 24$ & 0 \\
\hline
\end{tabular}

a $n=$ number of individual specimens in which GRBV was detected by multiplex polymerase chain reaction over the total number of specimens tested; - indicates no specimen tested. 
Sequenced-based insect species identification. A representative specimen of each of $O$. borealis (GenBank accession number MF414209), S. festinus (MF414211), and Melanoliarus sp. (MF414210) produced PCR amplicons of 648 to 708 bp in the COI "barcode" region. A specimen of the Melanoliarus sp. was identified to the genus level, with $94 \%$ nucleotide sequence identity to sample ID BIOUG02202A06 in the BOLD Systems database (www.boldsystems.org). The O. borealis specimen had $99.3 \%$ identity to sample ID BIOUG12705A04 in the database, which meets the diversity cut-off for species identification. Similarly, the $S$. festinus specimen revealed $100 \%$ identity to sample ID BIOUG02202-G07 in the database, verifying species identification. Specimens of $C$. reductus repeatedly failed to produce PCR products with the primer sets selected for this study.

Population dynamics of the vector candidates. The abundance of the four vector candidates captured on sticky cards was low relative to total insect abundance, with only 87 and 99 specimens in 2015 and 2016, respectively. Populations of the four vector candidates peaked between June and September during both years. Populations of S. festinus peaked during early July 2015 (Fig. 2A) and late June 2016 (Fig. 2B), with populations quickly tapering after July. Populations of C. reductus peaked in August 2015 (Fig. 2A) and in April and September 2016 (Fig. 2B). Populations of the Melanoliarus sp. peaked in July (Fig. 2). O. borealis was captured infrequently in June and July and increasingly in August and September of both years (Fig. 2).

GRBV was not detected in vector candidates until June (Fig. 3), with the exception of one $C$. reductus specimen that tested positive for GRBV in early May 2016 (Fig. 3F). The incidence of viruliferous S. festinus was highest in July 2015 (Fig. 3A) and June 2016 (Fig. 3B). Viruliferous $O$. borealis insects were detected from July to November 2015 (Fig. 3C) and 2016 (Fig. 3D), whereas the viruliferous Melanoliarus sp. was captured on sticky cards only from July to September (Fig. 3G and H).

GRBV sequence diversity from vector candidates and infected vines. The sequences of GRBV Rep fragments recovered from infected vines in the sampled area of the selected vineyard were nearly identical (>99\% identity at the nucleotide level) to each other and belonged to phylogenetic clade 2 (Fig. 4). Similar results were obtained for the GRBV CP fragments recovered from infected Cabernet franc vines (data not shown). These data were consistent with previous findings from the same Cabernet franc vineyard (Perry et al. 2016). The majority of GRBV Rep fragments (89\%, 56 of 63) recovered from the four vector candidates in this vineyard also showed high nucleotide sequence identity ( $>99 \%)$ to the corresponding fragments from infected vines (Fig. 4). This result revealed the genetic relatedness of GRBV isolates in infected vines and most of the viruliferous insect vector candidate specimens. However, a few GRBV Rep fragments (11\%, 7 of 63) recovered from vector candidate specimens of $S$. festinus, $O$. borealis, and $C$. reductus differed from the corresponding GRBV nucleotide sequence from infected vines in the Cabernet franc vineyard and belonged to clade 1 (Fig. 4). The phylogenetic lineage assembled from GRBV $C P$ sequences was consistent with that obtained from GRBV Rep sequences (data not shown).
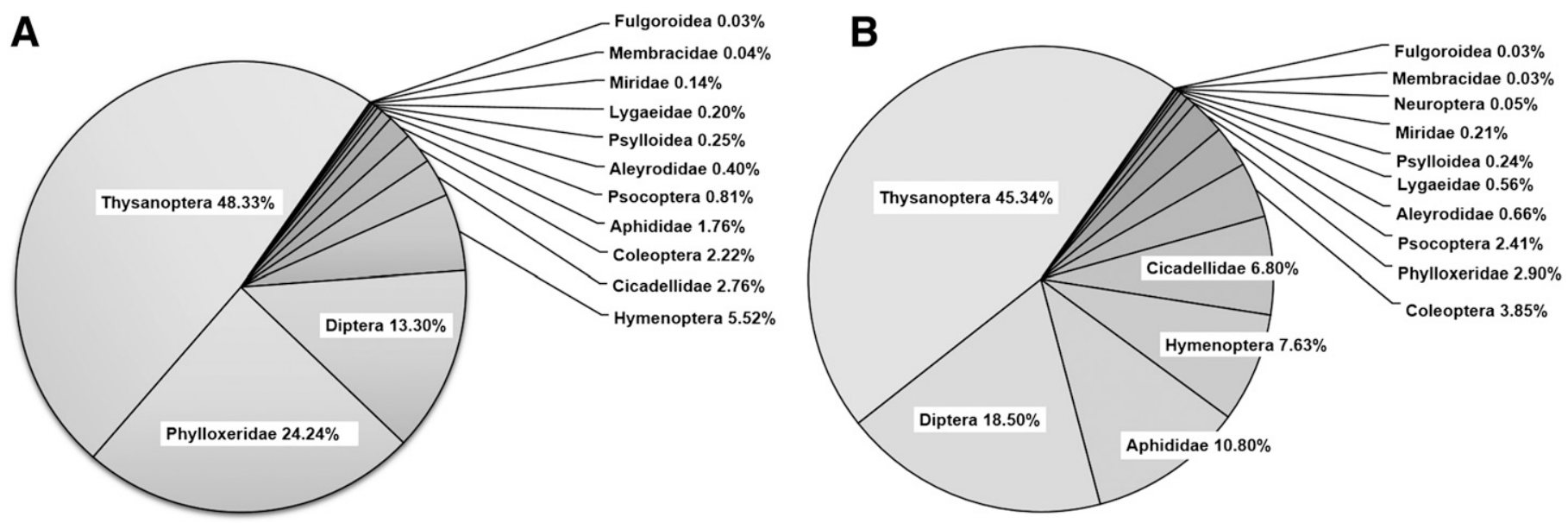

Fig. 1. Diversity and abundance of insect taxa identified from sticky cards placed in a Vitis vinifera 'Cabernet franc' vineyard infected by Grapevine red blotch virus in Napa County, CA in A, 2015 and B, 2016.

A

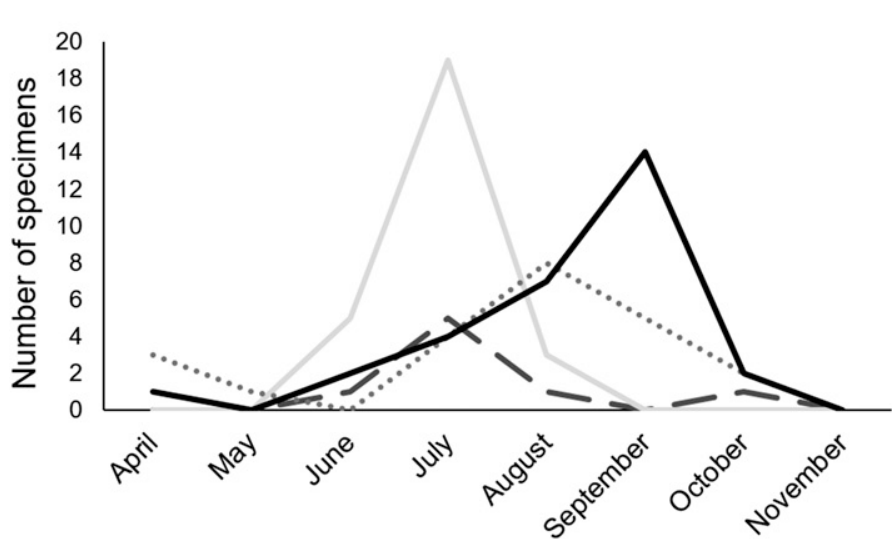

B

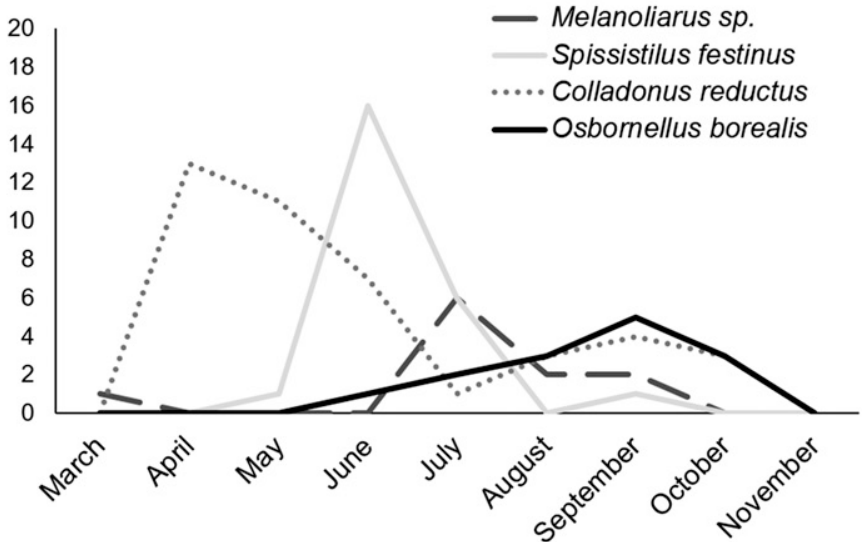

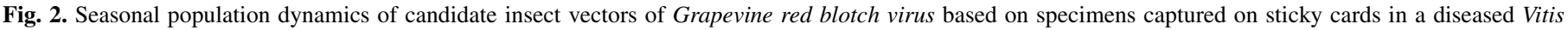
vinifera 'Cabernet franc' vineyard in Napa County, CA in A, 2015 and B, 2016. 
Spatial association of GRBV incidence in vines and vector candidates. Spatial pattern analyses indicated aggregated patterns of GRBV-infected vines and populations of $S$. festinus and $O$. borealis. No significant aggregation was found for $C$. reductus and the Melanoliarus sp. (Table 2). Moreover, there was a significant spatial association between the distribution of infected vines and viruliferous $S$. festinus. No significant spatial associations were identified between populations of alternative insect vector candidates and GRBV-infected vines (Table 3).
The spatial distribution of vector candidates on sticky cards also indicated a gradient of higher $S$. festinus $(n=50)$ and $O$. borealis $(n=42)$ populations at the edge of the vineyard next to a riparian area and decreasing $S$. festinus and $O$. borealis populations distant from the edge (Fig. 5). Additionally, both $S$. festinus and $O$. borealis populations of section 1 near the edge of the vineyard ( 0 to $10 \mathrm{~m}$ from the edge of the vineyard) had a higher proportion of viruliferous insects than the inner-vineyard section 2 (10 to $20 \mathrm{~m}$ within the vineyard) and section 3 (20 to $30 \mathrm{~m}$ within the vineyard), in which
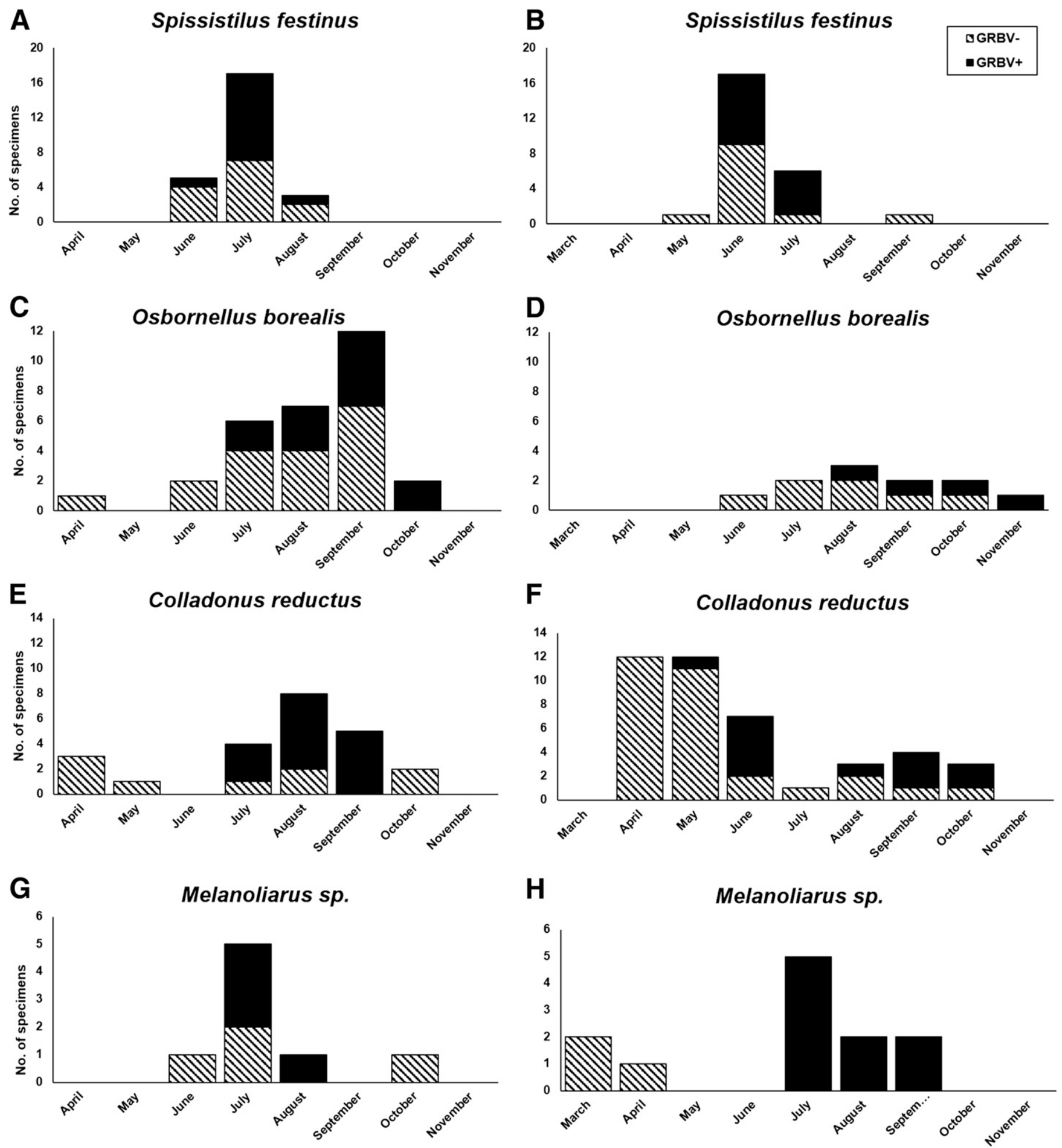

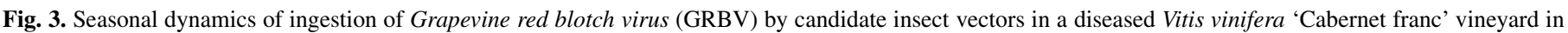

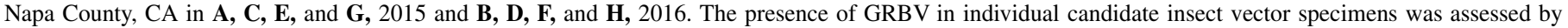
multiplex polymerase chain reaction. 
the proportions of viruliferous specimens were lower. The spatial distribution of $C$. reductus $(n=64)$ and Melanoliarus $(n=20)$ was not dependent upon proximity to the edge of the vineyard (Fig. 5).

\section{DISCUSSION}

We investigated the ecological aspects of GRBV in a commercial Cabernet franc vineyard for which secondary spread was previously documented (Cieniewicz et al. 2017b). In addition to S. festinus, a recognized vector of GRBV (Bahder et al. 2016a), three additional potential GRBV insect vectors were identified and their diversity, relative abundance, and seasonal distribution was described. To our knowledge, this is the first research on the epidemiological relevance of $S$. festinus as a vector of GRBV. It is also the first report on the seasonal acquisition of GRBV by $S$. festinus in a vineyard ecosystem. This study was initiated in 2015 , before there was any information on secondary spread of red blotch disease. Spatiotemporal analysis of spread in the same vineyard indicated a 1 to $2 \%$ increase in disease incidence annually, with the highest rate occurring near a riparian area (Cieniewicz et al. 2017b). In addition, the analysis of spread attributes of the epidemic indicated a limited influx of GRBV into the vineyard from background sources; rather, spread in this vineyard was due to local, within-vineyard sources of inoculum (Cieniewicz et al. 2017b). These conclusions were strengthened by the extremely high identity among GRBV sequences (99 to $100 \%$ nucleotide identity) recovered from newly infected vines in this vineyard in 2016 and the majority (89\%) of the viruliferous vector candidates trapped on sticky cards in 2015 and 2016. These results suggested that most of the vector candidate specimens ingested GRBV from the Cabernet franc vineyard where they were captured. An alternative explanation is that candidate vectors carried the same GRBV genetic variant as was present in infected Cabernet franc vines but acquired it before entering the vineyard. However, a few (11\%) specimens of S. festinus, O. borealis, and $C$. reductus carried GRBV Rep sequences that were distinct (88.7 to $94 \%$ nucleotide sequence identity) from GRBV Rep sequences in the infected vines and the majority of vector candidate specimens. This suggested that some vector candidates ingested GRBV from sources outside of the Cabernet franc vineyard and then visited the Cabernet franc vineyard to feed. A potential source of GRBV clade 1 isolates is a nearby Cabernet Sauvignon vineyard (Perry et al. 2016).
Altogether, our results indicated that GRBV can be ingested by vector candidates from both local (intravineyard) and background (extravineyard) sources. It will be important to determine whether comparable studies in other viticulture regions will lead to similar conclusions.

GRBV was only detected in the four vector candidates starting in June (with the exception of one C. reductus specimen in May 2016), suggesting that virus uptake and transmission is unlikely to occur prior to June in this vineyard. Additional studies are needed to verify whether findings from this Cabernet franc vineyard translate into similar trends in population dynamics in other vineyards. The disparity between 2015 and 2016 in the proportion of $C$. reductus that tested positive for GRBV is attributed to the higher number of specimens in April 2016, which all tested negative for GRBV, than the previous year. Additionally, the survey was initiated earlier in 2016 (March) than 2015 (April) and selection of specimens for GRBV testing by PCR preferentially targeted vector candidates in 2016.

Among the four vector candidates identified in this study, only S. festinus is known to transmit GRBV in the greenhouse (Bahder et al. 2016a). The population dynamics of $S$. festinus insects and their seasonal ingestion of GRBV were consistent between 2015 and 2016, with peaks in late June and early July. In addition, only viruliferous $S$. festinus populations were significantly associated

TABLE 2. Spatial analysis by distance indices of the spatial pattern of Grapevine red blotch virus (GRBV)-infected grapevines and candidate insect vector populations in 2015 and 2016

\begin{tabular}{lccl}
\hline Variable $^{\mathrm{a}}$ & $D^{\mathrm{b}}$ & $I_{a}^{\mathrm{c}}$ & \multicolumn{1}{c}{$P^{\mathrm{d}}$} \\
\hline GRBV incidence & 418.7 & 2.088 & $0.002^{* *}$ \\
Spissistilus festinus (total counts) & 156.8 & 1.171 & $0.137(\mathrm{~ns})$ \\
S. festinus (viruliferous counts) & 141.2 & 1.486 & $0.0099^{* *}$ \\
Osbornellus borealis (total counts) & 218.9 & 1.549 & $0.007^{* *}$ \\
O. borealis (viruliferous counts) & 136.3 & 1.702 & $0.0012^{* *}$ \\
Colladonus reductus (total counts) & 157.3 & 0.931 & $0.613(\mathrm{~ns})$ \\
C. reductus (viruliferous counts) & 127.1 & 1.305 & $0.052(\mathrm{~ns})$ \\
Melanoliarus sp. (total counts) & 64.4 & 0.853 & $0.833(\mathrm{~ns})$ \\
Melanoliarus sp. (viruliferous counts) & 58.5 & 0.7962 & $0.956(\mathrm{~ns})$ \\
\hline
\end{tabular}

${ }^{a}$ Total counts and total viruliferous specimen counts are provided for each candidate insect vector species.

${ }^{\text {b }} D=$ distance to regularity.

${ }^{\mathrm{c}} I_{a}=$ index of aggregation.

d Asterisks (**) indicate significance according to a two-tail test at $P<0.01$; ns $=$ not significant.

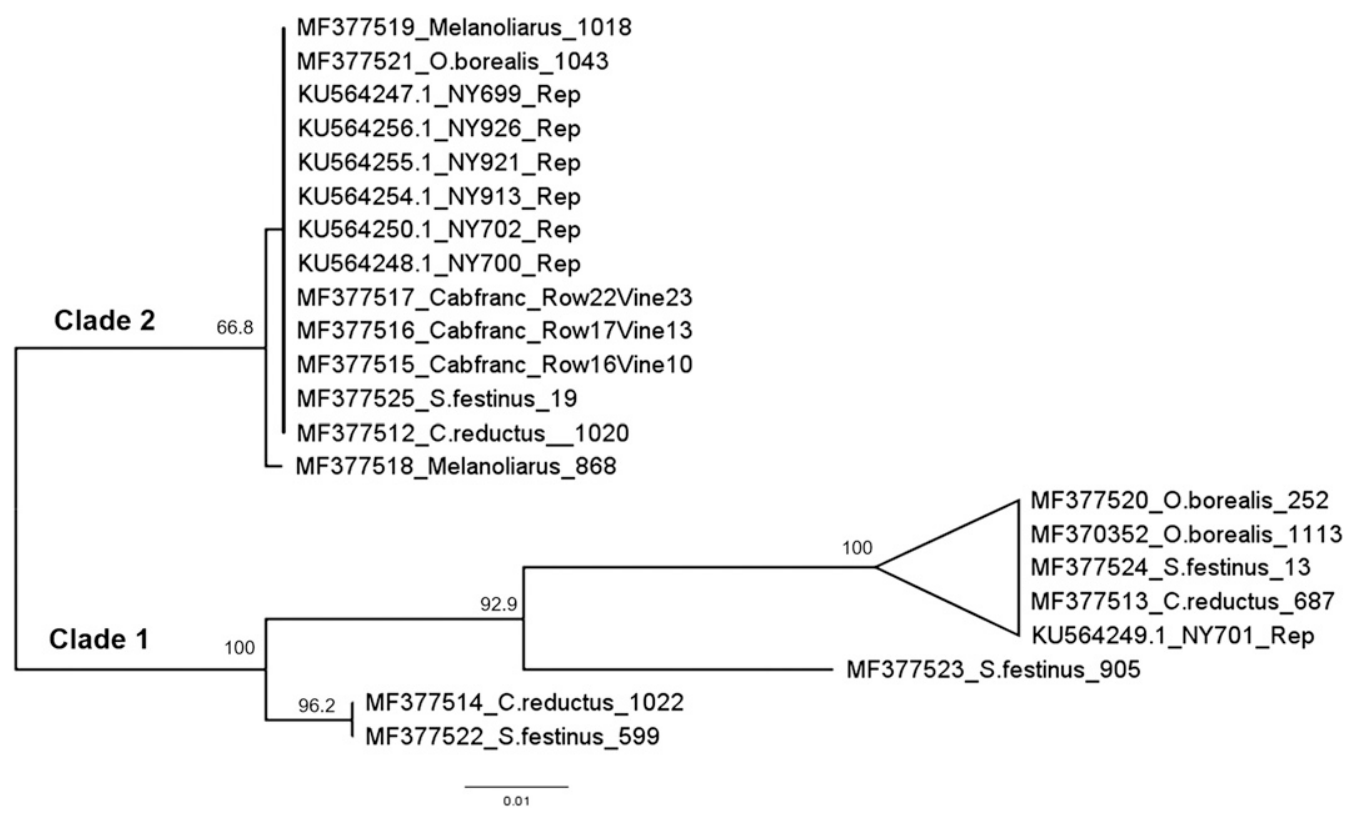

Fig. 4. Neighbor-joining phylogenetic tree indicating relationships among Grapevine red blotch virus (GRBV) replicase-associated protein (Rep) nucleic acid sequences recovered from infected Cabernet franc vines, candidate insect vectors (Melanoliarus sp., Spissistilus festinus, Colladonus reductus, and Osbornellus borealis) isolated from sticky cards, and nearby GRBV-infected free-living and commercial vines from a previous study (Perry et al. 2016). Branches with less than $65 \%$ bootstrap support were collapsed. Information on the source of GRBV Rep sequence information is provided in Supplementary Table S1. 
with the spatial pattern of infected vines, although the spatial pattern of viruliferous $O$. borealis showed a nearly significant $(P=0.089)$ association with the spatial pattern of infected vines. Also, a higher proportion of viruliferous $S$. festinus and $O$. borealis specimens were caught toward the edge of the vineyard and decreased further into the vineyard (Fig. 5). These results suggested a directional influx of aviruliferous $S$. festinus and $O$. borealis insects and a subsequent ingestion of GRBV primarily from infected vines located at the edge, proximal to a riparian area. No significant association was found for any of the other vector candidate populations. Although the lack of spatial association between infected vines and $C$. reductus, $O$. borealis, and the Melanoliarus

TABLE 3. Association analysis between spatial patterns of virus incidence and total candidate insect vector populations or viruliferous candidate insect vector populations using spatial analysis by distance indices with an actual sample size of 72

\begin{tabular}{lcc}
\hline & $\begin{array}{c}\text { Effective } \\
\text { sample } \\
\text { size }\end{array}$ & $\begin{array}{c}\text { Overall } \\
\text { association }(X)^{\mathrm{b}}\end{array}$ \\
Variable $^{\mathrm{a}}$ & 76.1 & $-0.0028(0.5094 ; \mathrm{ns})$ \\
\hline $\begin{array}{l}\text { Spissistilus festinus } \text { (total counts) } \\
\text { S. festinus (viruliferous counts) }\end{array}$ & 72.0 & $0.1989(0.0479 *)$ \\
$\begin{array}{l}\text { Osbornellus borealis (total } \\
\text { counts) }\end{array}$ & 73.0 & $0.1600(0.089 ; \mathrm{ns})$ \\
$\begin{array}{l}\text { O. borealis (viruliferous counts) } \\
\text { Colladonus reductus (total counts) }\end{array}$ & 67.8 & $0.1643(0.091 ; \mathrm{ns})$ \\
C. reductus (viruliferous counts) & 68.8 & $0.0810(0.263 ; \mathrm{ns})$ \\
$\begin{array}{l}\text { Melanoliarus sp. (total counts) } \\
\text { Melanoliarus sp. (viruliferous }\end{array}$ & 71.4 & $-0.0895(0.769 ; \mathrm{ns})$ \\
counts) & 72.2 & $0.075(0.529 ; \mathrm{ns})$ \\
\hline
\end{tabular}

a Total counts and total viruliferous specimen counts are provided for each candidate insect vector species.

b Overall association (X). Two-tail probability value presented parenthetically. An asterisk $(*)$ indicates significance according to a two-tail test at $P<0.05$; $\mathrm{ns}=$ not significant. sp. does not exclude these insects as vectors, this result supports the hypothesis that $S$. festinus is the predominant vector responsible for secondary spread of GRBV within this Cabernet franc vineyard.

No information is available on the vector potential of $O$. borealis, C. reductus, and the Melanoliarus sp., providing an impetus for controlled GRBV transmission assays. However, this field study advances our understanding of the vector biology of this pathosystem, for which limited information is available. A previous report suggested E. ziczac as a vector of GRBV (Poojari et al. 2013) but this finding was later refuted (Bahder et al. 2016a). In our study, this leafhopper was not captured on sticky card traps in 2015 and none of the 10 specimens caught in 2016 tested positive for GRBV. Additionally, E. ziczac is a mesophyll feeder (Saguez et al. 2015), which differs from the phloemfeeder vector candidates identified empirically in this study. Collectively, our observations provide vineyard-based evidence that does not support the supposition that E. ziczac is a vector of GRBV.

None of the four candidate vector species identified in our study is recognized as a pest of grapevine. However, their traits are consistent with predictions of a new type of insect vector for a grapevine virus based on the spatial attributes of a GRBV epidemic (Cieniewicz et al. 2017b). The four candidate insect vectors identified in this study feed preferentially on phloem or belong to genera of known phloem feeders. $O$. borealis has been implicated as a vector of the $\mathrm{X}$-disease phytoplasma (ribosomal group 16sRIII-I), affecting stone fruit and some reservoir hosts (Jensen 1957). Other species within the genus Colladonus (C. geminatus and $C$. montanus) also transmit the $\mathrm{X}$-disease phytoplasma (Wolfe 1955; Wolfe et al. 1950). S. festinus is a phloem feeder that girdles stems of plants on which it feeds (Mueller and Dumas 1975). Cixiid planthoppers such as the Melanoliarus sp. also feed on phloem, and some can transmit phytoplasmas, such as the lethal yellows phytoplasma in palm (Holzinger et al. 2002). By analogy with other geminivirids, GRBV is anticipated to be phloem restricted, adding significance to the identification of the four phloemfeeding vector candidates.
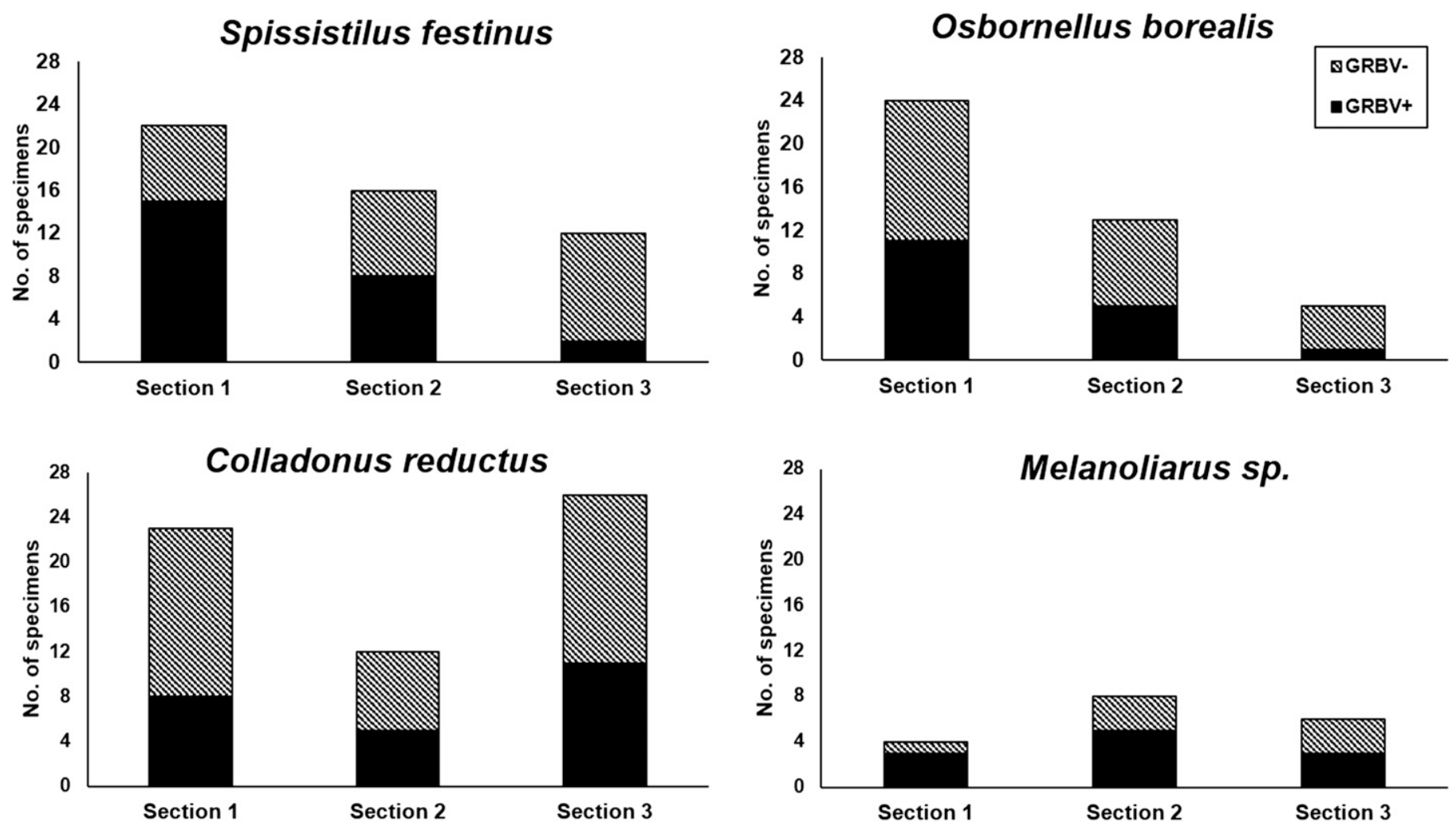

Fig. 5. Spatial distribution of candidate insect vectors at the edge of a Cabernet franc vineyard where Grapevine red blotch virus incidence is aggregated proximal to a riparian habitat. Numbers of specimens in 2015 and 2016 are summed for each species. Sections 1 ( 0 to $10 \mathrm{~m}$ from the edge of the vineyard), 2 ( 10 to $20 \mathrm{~m}$ within the vineyard), and 3 (20 to $30 \mathrm{~m}$ within the vineyard) indicate partitions of two four-vine panels, where section 1 is positioned closest to the edge and section 3 is furthest into the vineyard. 
Although the vector candidates are all phloem feeders, GRBV was not detected or not consistently detected in each of the phloem-feeding insects that were present on sticky card traps. A nonexhaustive list of examples of phloem feeders (Douglas 2006), in which GRBV was rarely or never detected by PCR, includes Scaphytopius magdalensis and Empoasca sp. leafhoppers, delphacid planthoppers, whiteflies, aphids, psyllids, and lygaeids. This could be attributed to a lack of or a lower rate of feeding on the infected Cabernet franc vines or an inability to ingest GRBV. Although GRBV was detected in a small percentage (3 to $8 \%$ ) of some of these phloem-feeders (S. magdalensis, the Empoasca sp., and aphids), the four vector candidates were highlighted as potential vectors, with the proportion of viruliferous specimens exceeding $40 \%$.

Yellow sticky cards were chosen as the sampling method to accomplish the goal of catching flying insects visiting the vines in the selected area of the study vineyard, including healthy and infected vines, and potentially feeding and ingesting GRBV. The sticky card sampling method likely resulted in undersampling populations of immature insects, as shown for other systems (Musser et al. 2004). Consequently, we cannot discount the possibility that some feeding insects were resistant to capture on sticky cards and, hence, potentially underrepresented in these findings. Therefore, the list of candidate vectors obtained here may not be exhaustive. Similarly, sticky cards may not be ideal for an accurate estimate of insect population densities. Other approaches such as sweep netting, vacuum traps, or UV light trapping may have added further information on vector candidate abundance. Nonetheless, our study suggested low population densities of vector candidates, with consistency over two consecutive years.

This study integrated unbiased survey outputs of GRBV ingestion by insects in a disease vineyard over two growing seasons and covariation analysis to reveal $S$. festinus as a vector of epidemiological significance. This research also revealed three additional candidate vectors of GRBV, which should be further evaluated for vectoring capabilities in controlled transmission assays to fundamentally advance vector biology. To our knowledge, the host range of the four vector candidates is poorly characterized. It will be critical to identify reproductive hosts in a vineyard ecosystem and determine whether some of them overlap with hosts of GRBV. This research is essential to advance our understanding of GRBV epidemiology and design optimal disease management strategies.

\section{ACKNOWLEDGMENTS}

We thank St. Supéry Vineyards and Winery in Rutherford, CA for sponsoring this research; J. Dombroskie at the Cornell University Insect Diagnostic Laboratory for his assistance with insect identification; and H. Sweet for assistance with insect testing. This work was supported, in part, by the California Grape Rootstock Research Foundation, the California Grape Rootstock Improvement Commission, the American Vineyard Foundation, the California Department of Food and Agriculture, the New York Grape and Wine Foundation, and the United States Department of Agriculture-National Institute of Food and Agriculture-Critical Agriculture Research and Extension award 2015-67028-23512.

\section{LITERATURE CITED}

Al Rwahnih, M., Ashita, D., Anderson, M., Rowhani, A., Uyemoto, J. K., and Sudarshana, M. R. 2013. Association of a DNA virus with grapevines affected by red blotch disease in California. Phytopathology 103:1069-1076.

Bahder, B. W., Zalom, F. G., Jayanth, M., and Sudarshana, M. R. 2016a. Phylogeny of geminivirus coat protein sequences and digital PCR aid in identifying Spissistilus festinus (Say) as a vector of Grapevine red blotchassociated virus. Phytopathology 106:1223-1230.

Bahder, B. W., Zalom, F. G., and Sudarshana, M. R. 2016b. An evaluation of the flora adjacent to wine grape vineyards for the presence of alternative host plants of Grapevine red blotch-associated virus. Plant Dis. 100:1571-1574.

Cieniewicz, E. J., Perry, K. L., and Fuchs, M. F. 2017a. Grapevine red blotch: Molecular biology of the virus and management of the disease. Pages 303-314 in: Grapevine Viruses: Molecular Biology, Diagnostics and Management. B. Meng, G. P. Martelli, D. Golino, and M. Fuchs, eds. Springer Verlag, Berlin.
Cieniewicz, E. J., Pethybridge, S. J., Gorny, A., Madden, L. V., McLane, H., Perry, K. L., and Fuchs, M. F. 2017b. Spatiotemporal spread of grapevine red blotch-associated virus in a California vineyard. Virus Res. 241:156-162.

Douglas, A. E. 2006. Phloem-sap feeding by animals: Problems and solutions. J. Exp. Bot. 57:747-54.

Dutilleul, P., Clifford, P., Richardson, S., and Hemon, D. 1993. Modifying the $t$ test for assessing the correlation between two spatial processes. Biometrics 49:305-314.

Folmer, O., Black, M., Hoeh, W., Lutz, R., and Vrijenhoek, R. 1994. DNA primers for amplification of mitochondrial cytochrome $\mathrm{c}$ oxidase subunit I from diverse metazoan invertebrates. J. Exp. Mar. Biol. Ecol. 3:294-299.

Foottit, R. G., Maw, E., and Hebert, P. D. N. 2014. DNA barcodes for nearctic Auchenorrhyncha (Insecta: Hemiptera). PLoS One 9:e101385.

Fuchs, M. F., Krenz, B., Yepes, L. M., Thompson, J., McLane, H., and Perry, K. L. 2015. Is Grapevine red blotch-associated virus the causal agent of red blotch disease? Pages 72-73 in: Proc. 18th Congr. Int. Counc. Study Virus Virus-like Dis. Grapevine, Ankara, Turkey.

Hebert, P. D. N., Cywinska, A., Ball, S. L., and Dewaard, J. R. 2003. Biological identifications through DNA barcodes. Proc. R. Soc. Lond. 270:313-21.

Hebert, P. D. N., Penton, E. H., Burns, J. M., Janzen, D. H., and Hallwachs, W. 2004. Ten species in one: DNA barcoding reveals cryptic species in the neotropical skipper butterfly Astraptes fulgerator. Proc. Natl. Acad. Sci. USA 101:14812-14817.

Holzinger, W. E., Emeljanov, A. F., and Kammerlander, I. 2002. The family Cixiidae (Spinola) 1839 (Hemiptera: Fulgoromorpha)—A review. Denisia 4:113-138.

Jensen, D. D. 1957. Transmission of peach yellow leaf roll virus by Fieberiella florii (Stal) and a new vector Osbornellus borealis (DeL. \& M.). J. Econ. Entomol. 50:668-672.

Krenz, B., Thompson, J., Fuchs, M. F., and Perry, K. L. 2012. Complete genome sequence of a new circular DNA virus from grapevine. J. Virol. 86:7715.

Krenz, B., Thompson, J., McLane, H., Fuchs, M. F., and Perry, K. L. 2014. Grapevine red blotch-associated virus is widespread in the United States. Phytopathology 104:1232-1240.

Li, B., Madden, L. V., and Xu, X. 2012. Spatial analysis by distance indices: An alternative local clustering index for studying spatial patterns. Methods Ecol. Evol. 3:368-377.

Lim, S., Igori, D., Zhao, F., and Moon, J. S. 2016. First report of Grapevine red blotch-associated virus on grapevine in Korea. Plant Dis. 100:1957.

Mueller, A. J., and Dumas, B. A. 1975. Effects of stem girdling by the threecornered alfalfa hopper on soybean yields. J. Econ. Entomol. 68:511-512.

Musser, F. R., Nyrop, J. P., and Shelton, A. M. 2004. Survey of predators and sampling method comparison in sweet corn. J. Econ. Entomol. 97:136-144.

Perry, J. N. 1995. Spatial analysis by distance indices. J. Anim. Ecol. 64: 303-314.

Perry, J. N. 1998. Measures of spatial pattern for counts. Ecology 79:1008-1017.

Perry, J. N., Winder, L., Holland, J. M., and Alston, R. D. 1999. Red-blue plots for detecting clusters in count data. Ecol. Lett. 2:106-113.

Perry, K. L., McLane, H., Hyder, M. Z., Dangl, G. S., Thompson, J. R., and Fuchs, M. F. 2016. Grapevine red blotch-associated virus is present in freeliving Vitis sp. proximal to cultivated grapevines. Phytopathology 106:663-670.

Poojari, S., Alabi, O. J., Fofanov, V. Y., and Naidu, R. A. 2013. A leafhoppertransmissible DNA virus with novel evolutionary lineage in the family Geminiviridae implicated in grapevine redleaf disease by next-generation sequencing. PLoS One 8:e64194.

Poojari, S., Lowery, D. T., Rott, M., Schmidt A. M. and Úrbez-Torres, J. R. 2017. Incidence, distribution and genetic diversity of Grapevine red blotch virus in British Columbia. Can. J. Plant Pathol. 39:201-211.

Reynard, J. S. 2015. Survey of emerging viruses in Switzerland. Pages 223224 in: Proc. 18th Congr. Int. Counc. Study Virus Virus-like Dis. Grapevine, Ankara, Turkey.

Ricketts, K. D., Gomez, M. I., Fuchs, M. F., Martinson, T. E., Smith, R. J., Cooper, M. L., and Wise, A. 2017. Mitigating the economic impact of Grapevine Red Blotch: Optimizing disease management strategies in U.S. vineyards. Am. J. Enol. Vitic. 68:127-135.

Saguez, J., Lemoyne, P., Giordanengo, P., Olivier, C., Lasnier, J., Mauffette, Y., and Vincent, C. 2015. Characterization of the feeding behavior of three Erythroneura species on grapevine by histological and DC-electrical penetration graph techniques. Entomol. Exp. Appl. 157:227-240.

Saitou, N., and Nei, M. 1987. The neighbor-joining method: A new method for reconstructing phylogenetic trees. Mol. Biol. Evol. 4:406-425.

Sudarshana, M. R., Perry, K. L., and Fuchs, M. F. 2015. Grapevine red blotchassociated virus, an emerging threat to the grapevine industry. Phytopathology 105:1026-1032.

Thompson, J. D., Gibson, T. J., Plewniak, F., Jeanmougin, F., and Higgins, D. G. 1997. The CLUSTAL_X windows interface: Flexible strategies for multiple sequence alignment aided by quality analysis tools. Nucleic Acids Res. 25:4876-4882. 
Varsani, A., Roumagnac, P., Fuchs, M., Navas-Castillo, J., Moriones, E., Idris, A., Briddon, R. W., Rivera-Bustamante, R., Zerbini, F. M., and Martin, D. P. 2017. Capulavirus and Grablovirus: Two new genera in the family Geminiviridae. Arch. Virol. 162:1819-1831.

Winder, L., Alexander, C. J., Holland, J. M., Woolley, C., and Perry, J. N. 2001. Modelling the dynamic spatio-temporal response of predators to transient prey patches in the field. Ecol. Lett. 4:568-576.
Wolfe, H. R. 1955. Transmission of the Western X disease virus by the leafhopper Colladonus montanus (Van D.). Plant Dis. Rep. 39:298-299.

Wolfe, H. R., Anthon, E. W., and Jones, S. L. 1950. Transmission of Western $\mathrm{X}$-disease of peaches by the leafhopper Colladonus geminatus (Van D.). (Abstr.) Phytopathology 40:971.

Xu, X., and Madden, L. V. 2005. Interrelationships among SADIE indices for characterizing spatial patterns of organisms. Phytopathology 95:874-883. 